\title{
Synthesis and Characterization of Hyperbranched Aromatic Poly(ether imide)s with Terminal Amino Groups
}

\author{
YAO-TE CHANG, ${ }^{1}$ CHING-FONG SHU, ${ }^{1}$ CHYI-MING LEU, ${ }^{2}$ KUNG-HWA WEI ${ }^{2}$ \\ ${ }^{1}$ Department of Applied Chemistry, National Chiao Tung University, Hsin-Chu, Taiwan 30035, Republic of China \\ ${ }^{2}$ Department of Materials Science and Engineering, National Chiao Tung University, Hsin-Chu, Taiwan 30035, \\ Republic of China
}

Received 29 April 2003; accepted 26 July 2003

\begin{abstract}
We synthesized an $\mathrm{AB}_{2}$-type monomer, 4-\{4-[di(4-aminophenyl)methyl]phenoxy\}phthalic acid, which contained one phthalic acid group and two aminophenyl functionalities. The direct self-polycondensation of the $\mathrm{AB}_{2}$-type monomer in the presence of triphenylphosphite as an activator afforded a hyperbranched poly(ether imide) with a large number of terminal amino groups. This polymer was characterized with ${ }^{1} \mathrm{H}$ NMR and IR spectroscopy. The degree of branching of the hyperbranched poly(ether imide) was approximately $56 \%$, as determined by a combination of model compound studies and an analysis of ${ }^{1} \mathrm{H}$ NMR spectroscopy integration data. The terminal amino groups underwent functionalization readily. The solubility and thermal properties of the resulting polymers depended on the nature of the chain end groups. In addition, the hyperbranched poly(ether imide) was grafted with polyhedral oligomeric silsesquioxane (POSS). Transmission electron microscopy analysis revealed that the grafted POSS molecules aggregated to form a nanocomposite material. () 2003 Wiley Periodicals, Inc. J Polym Sci Part A: Polym Chem 41: 3726-3735, 2003
\end{abstract}

Keywords: $\mathrm{AB}_{2}$ monomer; degree of branching; hyperbranched; nanocomposites; poly(ether imide); TEM

\section{INTRODUCTION}

Hyperbranched polymers have been the subject of considerable interest because their unique highly branched structures and surface functionalities confer upon them some unusual properties. ${ }^{1-4}$ As predicted theoretically by Flory, ${ }^{5}$ these polymers can be conveniently prepared in a single step by the one-pot polymerization of $\mathrm{AB}_{n}$-type monomers to produce highly branched, irregular structures that contain a large number of terminal functional groups. Nevertheless, these polymers still maintain many of the architectural features and

Correspondence to: C.-F. Shu (E-mail: shu@cc.nctu.edu.tw) Journal of Polymer Science: Part A: Polymer Chemistry, Vol. 41, 3726-3735 (2003) ๑) 2003 Wiley Periodicals, Inc. properties found in their well-defined dendrimer counterparts, ${ }^{6-10}$ which are built up through synthetic sequences with isolation and purification at each step. ${ }^{11-14}$ The one-step synthesis is attractive because it allows hyperbranched polymers to be more readily prepared on a large scale for any potential applications.

The excellent thermal, mechanical, and electrical properties of aromatic poly(ether imide)s make them suitable for use as high-performance polymer materials. ${ }^{15,16}$ The preparation of traditional linear poly(ether imide)s has been carried out typically by two methods, the first of which is a synthesis involving the condensation of dianhydride and diamine monomers, thus generating poly(amic acid), followed by cyclodehydration to form the imide ring. ${ }^{17}$ The second method uses 
aromatic nucleophilic substitution reactions of phenoxide nucleophiles with nitro- or fluoro-substituted phthalimides to form the ether linkage. ${ }^{18}$ Generally, hyperbranched polymers are prepared by the self-condensation of $\mathrm{AB}_{2}$-type monomers. Because of the high reactivity of amine and anhydride functionalities, there is no stable $\mathrm{AB}_{2^{-}}$ type monomer containing one amino group and two anhydride groups (or one anhydride group and two amino groups) available for the preparation of hyperbranched poly(ether imide)s. To overcome this problem, Moore and coworkers ${ }^{19-21}$ reported a modification of the nucleophilic displacement method for the preparation of hyperbranched poly(ether imide)s that used a Krickeldorf-type reaction involving tert-butyldimethylsilyl-protected benzenediol groups and an activated fluoride in the presence of a catalytic amount of CsF. Kakimoto et al. ${ }^{22-24}$ prepared hyperbranched poly(ether imide)s from a monomer consisting of an amino group and a phthalic acid monomethyl ester. In a previous study, we reported that hyperbranched poly(ether imide)s could be prepared by the aromatic nucleophilic substitution of an $\mathrm{AB}_{2}$ monomer containing two phenol groups and a fluoro-substituted phthalimide unit. ${ }^{25}$ More recently, the syntheses of hyperbranched aromatic polyimides with an $\mathrm{A}_{2}+\mathrm{B}_{3}$ (or $\mathrm{BB}^{\prime}{ }_{2}$ ) approach have also been reported. ${ }^{26-29}$

This report describes an alternative synthetic approach for the preparation of hyperbranched poly(ether imide)s. In this procedure, the imide rings are formed by the direct self-polycondensation of a substituted phthalic acid, which contains two aminophenyl groups in the same molecule, with triphenylphosphite (TPP) as an activator. ${ }^{30}$ Thus, an $\mathrm{AB}_{2}$-type monomer, 4-\{4-[di(4-aminophenyl)methyl]phenoxy\}phthalic acid (3), was synthesized, and its subsequent self-polymerization led to the formation of a hyperbranched poly(ether imide) possessing a large number of terminal amino groups. It is noteworthy that the NMR spectroscopy signals of the methine protons of the hyperbranched polymer obtained in this way can indicate the degree of branching (DB) of the polymer (as discussed later). Through the chemical modification of the terminal amino groups, a variety of different functional groups were introduced into the hyperbranched poly(ether imide). We investigated the effects that particular terminal functional groups had on the physical properties of these hyperbranched poly(ether imide)s. Furthermore, a hyperbranched poly(ether imide) was grafted with polyhedral oligomeric silsesqui- oxane/benzyl chloride (POSS-BzCl) through the terminal amino groups to form an organic-inorganic hybrid material. ${ }^{31}$ The morphology of this hybrid material was examined by means of transmission electron microscopy (TEM), which indicated that the grafted polyhedral oligomeric silsesquioxane (POSS) molecules probably aggregated to form a nanoscale composite material with a defined architecture.

\section{EXPERIMENTAL}

\section{General Directions}

Unless otherwise stated, all the reagents and solvents were used as received from commercial sources. $N$-Methyl-2-pyrrolidinone (NMP) was distilled over $\mathrm{CaH}_{2}$ under reduced pressure. Pyridine was dried by distillation after being heated under reflux in the presence of KOH. TPP was purified by distillation under reduced pressure. POSS- $\mathrm{BzCl}$ was purchased from Hybrid Plastics. ${ }^{1} \mathrm{H}$ and ${ }^{13} \mathrm{C}$ NMR spectra were recorded on a Varian Unity $300-\mathrm{MHz}$ spectrometer or a BrukerDRX 300-MHz spectrometer. IR spectra were obtained on a Nicolet 360 Fourier transform infrared (FTIR) spectrometer. Mass spectra were recorded on a JEOL JMS-SX 102A mass spectrometer. Gel permeation chromatography (GPC) was carried out on a Waters chromatography unit interfaced with a Waters 410 differential refractometer. We used three 5 - $\mu \mathrm{m}$ Waters Styragel columns $(300 \times 7.8 \mathrm{~mm})$, connected in series in decreasing order of pore size $\left(10^{5}, 10^{4}\right.$, and $\left.10^{3} \AA\right)$, with dimethylformamide (DMF) as the eluent; standard samples of poly(methyl methacrylate) were used for calibration. Differential scanning calorimetry (DSC) was performed with a DuPont TA 2000 instrument, with a heating/cooling rate of $20^{\circ} \mathrm{C} \mathrm{min}{ }^{-1}$. Samples were scanned from 30 to $300{ }^{\circ} \mathrm{C}$, cooled to $30^{\circ} \mathrm{C}$, and then scanned a second time from 30 to $300{ }^{\circ} \mathrm{C}$. The glass-transition temperature $\left(T_{\mathrm{g}}\right)$ was determined from the second heating scan. Thermogravimetric analysis (TGA) was performed on a DuPont TGA 2950 instrument. The thermal stability of the samples was determined under a nitrogen atmosphere by the measurement of the weight loss during heating at a rate of $20{ }^{\circ} \mathrm{C} \min ^{-1}$. The TEM measurements were conducted on a JEOL-2000FX instrument with an acceleration voltage of $200 \mathrm{kV}$.

\section{4-[Di(4-aminophenyl)methyl]phenol (1)}

A mixture of 4-hydroxybenzaldehyde $(5.00 \mathrm{~g}, 41.0$ $\mathrm{mmol})$, aniline (13.20 g, $141.9 \mathrm{mmol})$, and aniline 
hydrochloride $(0.31 \mathrm{~g}, 2.42 \mathrm{mmol})$ was heated at $150{ }^{\circ} \mathrm{C}$ under a nitrogen atmosphere for $1.5 \mathrm{~h}$. The excess aniline was then evaporated under reduced pressure. The residue was added to water $(60 \mathrm{~mL})$ and extracted with ethyl acetate $(3 \times 100$ $\mathrm{mL}$ ). The combined extracts were dried over $\mathrm{MgSO}_{4}$, and the solvent was evaporated. The product was purified by recrystallization from ethyl acetate and then recrystallization from ethanol to afford $\mathbf{1}$ (7.00 g, 58.9\%).

${ }^{1} \mathrm{H}$ NMR [deuterated dimethyl sulfoxide $\left(\mathrm{DMSO}-d_{6}\right), \delta$ ]: $4.80(\mathrm{br}, 4 \mathrm{H}), 5.06(\mathrm{~s}, 1 \mathrm{H}), 6.48(\mathrm{~d}$, $J=8.1 \mathrm{~Hz}, 4 \mathrm{H}), 6.65(\mathrm{~d}, J=8.4 \mathrm{~Hz}, 2 \mathrm{H}), 6.72(\mathrm{~d}$, $J=8.1 \mathrm{~Hz}, 4 \mathrm{H}), 6.85(\mathrm{~d}, J=8.4 \mathrm{~Hz}, 2 \mathrm{H}), 9.28(\mathrm{~s}$, $1 \mathrm{H}) .{ }^{13} \mathrm{C}$ NMR (DMSO- $d_{6}, \delta$ ): $54.1,114.1,115.0$, 129.6, 130.0, 133.0, 136.3, 146.5, 155.3. High-resolution mass spectrometry (HRMS): $\left[\mathrm{M}^{+}\right]$calcd. for $\mathrm{C}_{19} \mathrm{H}_{18} \mathrm{~N}_{2} \mathrm{O}$, 290.1419; found, 290.1423.

\section{4-\{4-[Di(4-aminophenyl)- methyl]phenoxy\}phthalonitrile (2)}

Potassium carbonate $(5.00 \mathrm{~g}, 36.2 \mathrm{mmol})$ was added to a solution of $\mathbf{1}(5.00 \mathrm{~g}, 17.2 \mathrm{mmol})$ and 4-nitrophthalonitrile (2.99 g, $17.3 \mathrm{mmol})$ in DMF $(20 \mathrm{~mL})$. The mixture was stirred at $130{ }^{\circ} \mathrm{C}$ for $12 \mathrm{~h}$ under nitrogen. After cooling, the solution was poured slowly into water $(120 \mathrm{~mL})$. The precipitated product was collected by filtration, dried in vacuo, and purified by column chromatography (1:1 hexane/ethyl acetate) to afford $2(5.04 \mathrm{~g}$, $70.4 \%)$.

${ }^{1} \mathrm{H}$ NMR (DMSO- $\left.d_{6}, \delta\right): 4.91(\mathrm{~s}, 4 \mathrm{H}), 5.22(\mathrm{~s}$, $1 \mathrm{H}), 6.49(\mathrm{~d}, J=8.4 \mathrm{~Hz}, 4 \mathrm{H}), 6.76(\mathrm{~d}, J=8.4 \mathrm{~Hz}$, $4 \mathrm{H}), 7.06(\mathrm{~d}, J=8.7 \mathrm{~Hz}, 2 \mathrm{H}), 7.16(\mathrm{~d}, J=8.7 \mathrm{~Hz}$, $2 \mathrm{H}), 7.32(\mathrm{dd}, J=8.7,2.6 \mathrm{~Hz}, 1 \mathrm{H}), 7.76(\mathrm{~d}, J=2.6$ $\mathrm{Hz}, 1 \mathrm{H}), 8.04(\mathrm{~d}, J=8.7 \mathrm{~Hz}, 1 \mathrm{H}) .{ }^{13} \mathrm{C} \mathrm{NMR}$ $\left(\right.$ DMSO- $\left.d_{6}, \delta\right)$ : $54.1,108.0,114.0,115.5,116.1$, $116.7,120.0,121.8,122.6,129.5,130.9,131.8$, 136.4, 143.5, 146.7, 151.6, 161.3. HRMS: $\left[\mathrm{M}^{+}\right]$ calcd. for $\mathrm{C}_{27} \mathrm{H}_{20} \mathrm{~N}_{4} \mathrm{O}, 416.1637$; found, 416.1631 .

\section{4-\{4-[Di(4-aminophenyl)methyl]phenoxy\}phthalic Acid (3)}

A solution of potassium hydroxide $(9.0 \mathrm{~g})$ in a mixture of water $(60 \mathrm{~mL})$ and ethanol $(90 \mathrm{~mL})$ was added to compound $2(3.00 \mathrm{~g}, 7.21 \mathrm{mmol})$. The mixture was then heated under reflux for $12 \mathrm{~h}$. The solution was diluted with water $(200 \mathrm{~mL})$ and acidified with $1 \mathrm{~N} \mathrm{HCl}$ (aqueous) to $\mathrm{pH} \sim 4$. The precipitated product was filtered, washed thoroughly with water, and dried to give 3 (3.09 g, $94.3 \%)$.
${ }^{1} \mathrm{H}$ NMR (DMSO- $\left.d_{6}, \delta\right): 5.22(\mathrm{~s}, 1 \mathrm{H}), 6.51(\mathrm{~d}, J$ $=8.4 \mathrm{~Hz}, 4 \mathrm{H}), 6.76(\mathrm{~d}, J=8.4 \mathrm{~Hz}, 4 \mathrm{H}), 7.00(\mathrm{~d}, J$ $=8.7 \mathrm{~Hz}, 2 \mathrm{H}), 7.07$ (dd, $J=8.7,2.4 \mathrm{~Hz}, 1 \mathrm{H}), 7.10$ $(\mathrm{d}, J=8.7 \mathrm{~Hz}, 2 \mathrm{H}), 7.33(\mathrm{~d}, J=2.4 \mathrm{~Hz}, 1 \mathrm{H}), 7.93$ $(\mathrm{d}, J=8.7 \mathrm{~Hz}, 1 \mathrm{H}) .{ }^{13} \mathrm{C}$ NMR (DMSO- $\left.d_{6}, \delta\right): 54.0$, $115.1,117.3,118.7,119.6,126.3,129.5,130.7$, $132.3,133.4,136.8,141.9,144.5,152.9,159.4$, 167.5, 168.4. HRMS: $\left[\mathrm{M}^{+}+\mathrm{H}\right]$ calcd. for $\mathrm{C}_{27} \mathrm{H}_{23} \mathrm{~N}_{2} \mathrm{O}_{5}$, 455.1607; found, 455.1599 .

\section{Synthesis of Model Compound 4}

TPP (0.12 mL, $0.45 \mathrm{mmol})$ was added to a solution of 3 (200 mg, $440 \mu \mathrm{mol})$ and 4- $n$-butylaniline (660 $\mathrm{mg}, 4.43 \mathrm{mmol}$ ) in NMP/pyridine (2.5 mL, $4: 1 \mathrm{v} / \mathrm{v})$, and the mixture was then heated at $150{ }^{\circ} \mathrm{C}$ for $12 \mathrm{~h}$. The mixture was poured into water $(20 \mathrm{~mL})$ and extracted with ethyl acetate $(3 \times 20 \mathrm{~mL})$. The combined extracts were dried over $\mathrm{MgSO}_{4}$, evaporated to dryness, and purified by column chromatography (1:1 hexane/ethyl acetate) to afford 4 (125 mg, 50.1\%).

${ }^{1} \mathrm{H}$ NMR (DMSO- $\left.d_{6}, \delta\right): 0.90(\mathrm{t}, J=7.5 \mathrm{~Hz}, 3 \mathrm{H})$, $1.26-1.37(\mathrm{~m}, 2 \mathrm{H}), 1.53-1.63(\mathrm{~m}, 2 \mathrm{H}), 2.62(\mathrm{t}, J$ $=7.8 \mathrm{~Hz}, 2 \mathrm{H}), 4.94(\mathrm{~s}, 4 \mathrm{H}), 5.23(\mathrm{~s}, 1 \mathrm{H}), 6.49(\mathrm{~d}, J$ $=8.4 \mathrm{~Hz}, 4 \mathrm{H}), 6.76(\mathrm{~d}, J=8.4 \mathrm{~Hz}, 4 \mathrm{H}), 7.08(\mathrm{~d}, J$ $=8.4 \mathrm{~Hz}, 2 \mathrm{H}), 7.16(\mathrm{~d}, J=8.4 \mathrm{~Hz}, 2 \mathrm{H}), 7.27-7.33$ (m, 5H), 7.37 (dd, $J=8.1,1.8 \mathrm{~Hz}, 1 \mathrm{H}), 7.93(\mathrm{~d}, J$ $=8.4 \mathrm{~Hz}, 1 \mathrm{H}) .{ }^{13} \mathrm{C}$ NMR $\left(\right.$ DMSO- $\left.d_{6}, \delta\right): 13.8,21.8$, $33.1,34.5,53.9,111.4,113.8,119.8,122.6,125.2$, $125.8,127.1,128.7,129.4,129.4,130.8,131.7$, $134.2,142.4,143.0,146.7,152.5,163.0,166.4$, 166.5. HRMS: $\left[\mathrm{M}^{+}\right]$calcd. for $\mathrm{C}_{37} \mathrm{H}_{33} \mathrm{~N}_{3} \mathrm{O}_{3}$, 567.2522; found, 567.2517.

\section{Synthesis of Model Compounds 5 and 6}

A solution of compound 4 (60 mg, $0.11 \mathrm{mmol}$ ) and phthalic anhydride $(20 \mathrm{mg}, 0.14 \mathrm{mmol})$ in dimethylacetamide (DMAc; $1.5 \mathrm{~mL}$ ) was heated at $150{ }^{\circ} \mathrm{C}$ under nitrogen for $6 \mathrm{~h}$. The resulting mixture was added to water $(20 \mathrm{~mL})$ and extracted with ethyl acetate $(3 \times 20 \mathrm{~mL})$. The combined extracts were dried over $\mathrm{MgSO}_{4}$, and the solvent was evaporated in vacuo. The products were purified by column chromatography (1:1 hexane/ ethyl acetate).

\section{Compound 5}

${ }^{1} \mathrm{H}$ NMR (DMSO- $\left.d_{6}, \delta\right): 0.90(\mathrm{t}, J=7.5 \mathrm{~Hz}, 3 \mathrm{H})$, $1.27-1.36(\mathrm{~m}, 2 \mathrm{H}), 1.53-1.61(\mathrm{~m}, 2 \mathrm{H}) 2.62(\mathrm{t}, J$ $=7.5 \mathrm{~Hz}, 2 \mathrm{H}), 5.00(\mathrm{~s}, 2 \mathrm{H}), 5.54(\mathrm{~s}, 1 \mathrm{H}), 6.53(\mathrm{~d}, J$ $=8.1 \mathrm{~Hz}, 2 \mathrm{H}), 6.84(\mathrm{~d}, J=8.1 \mathrm{~Hz}, 2 \mathrm{H}), 7.14(\mathrm{~d}, J$ 
$=8.7 \mathrm{~Hz}, 2 \mathrm{H}), 7.20-7.42(\mathrm{~m}, 12 \mathrm{H}), 7.84-8.00(\mathrm{~m}$, $5 \mathrm{H}) .{ }^{13} \mathrm{C}$ NMR (DMSO- $\left.d_{6}, \delta\right): 13.8,21.8,33.1$, 34.5, 54.2, 111.6, 113.9, 120.0, 122.7, 123.4, 125.3, $125.8,127.1,128.7,129.3,129.5,129.8,130.2$, $130.9,131.5,134.3,134.7,141.6,142.4,144.6$, 147.1, 152.9, 162.8, 166.4, 166.5, 167.1. HRMS: $\left[\mathrm{M}^{+}\right]$calcd. for $\mathrm{C}_{45} \mathrm{H}_{35} \mathrm{~N}_{3} \mathrm{O}_{5}, 697.2577$; found, 697.2603 .

\section{Compound 6}

${ }^{1} \mathrm{H}$ NMR (DMSO- $\left.d_{6}, \delta\right): 0.90(\mathrm{t}, J=7.2 \mathrm{~Hz}, 3 \mathrm{H}$ ), 1.27-1.36 (m, 2H), 1.53-1.61 (m, 2H), $2.62(\mathrm{t}, J$ $=7.2 \mathrm{~Hz}, 2 \mathrm{H}), 5.87(\mathrm{~s}, 1 \mathrm{H}), 7.20(\mathrm{~d}, J=7.8 \mathrm{~Hz}$, $2 \mathrm{H}), 7.24-7.50(\mathrm{~m}, 16 \mathrm{H}), 7.80-8.0(\mathrm{~m}, 5 \mathrm{H}) .{ }^{13} \mathrm{C}$ NMR (DMSO- $d_{6}, \delta$ ): 13.8, 21.8, 33.1, 34.5, 54.4, $111.9,120.3,122.8,123.5,125.4,125.9,127.1$, $127.4,128.7,129.5,130.2,131.1,131.5,134.3$, $134.7,140.2,142.4,143.3,153.3,162.7,166.3$, 166.5, 167.0. HRMS: $\left[\mathrm{M}^{+}\right]$calcd. for $\mathrm{C}_{53} \mathrm{H}_{37} \mathrm{~N}_{3} \mathrm{O}_{7}$, 827.2631; found, 827.2623.

\section{Preparation of Polymer PEI-1}

A solution of 3 (700 mg, $1.54 \mathrm{mmol}$ ) and TPP (400 $\mu \mathrm{L}, 1.54 \mathrm{mmol}$ ) in NMP/pyridine (35 mL, 4:1 v/v) was heated at $150{ }^{\circ} \mathrm{C}$ under nitrogen for $12 \mathrm{~h}$. After cooling, the resulting polymer was precipitated into methanol. The polymer was collected, purified twice by reprecipitation from DMF into methanol, and dried in vacuo to give PEI-1 (630 $\mathrm{mg}, 97.6 \%)$.

${ }^{1} \mathrm{H}$ NMR (DMSO- $\left.d_{6}, \delta\right): 4.98$ (br, 2H), 5.19-5.86 $(\mathrm{m}, 1 \mathrm{H}), 6.42-6.58(\mathrm{~m}, 2 \mathrm{H}), 6.70-6.88(\mathrm{~m}, 2 \mathrm{H})$, 7.00-7.40 (m, 10H), 7.92 (br, 1H). IR (KBr): 3457, $3365(\mathrm{~N}-\mathrm{H}), 1778,1721(\mathrm{C}=\mathrm{O}$, imide ring), 1373 $\mathrm{cm}^{-1}(\mathrm{C}-\mathrm{N}$, imide).

\section{Preparation of Polymer PEI-2}

Acetyl chloride $(1.0 \mathrm{~mL})$ was added dropwise under nitrogen to a solution of PEI-1 (100 mg, 240 $\mu \mathrm{mol})$ in DMAc $(2.0 \mathrm{~mL})$ at $0{ }^{\circ} \mathrm{C}$. After the addition was complete, the mixture was stirred at $0{ }^{\circ} \mathrm{C}$ for $2 \mathrm{~h}$ and then at $25{ }^{\circ} \mathrm{C}$ for $6 \mathrm{~h}$. The resulting solution was added dropwise to methanol $(50 \mathrm{~mL})$ with agitation. The polymer was collected by filtration, purified twice by reprecipitation from $\mathrm{DMF}$ into methanol, and dried in vacuo to give PEI-2 (95 mg, 90\%).

${ }^{1} \mathrm{H}$ NMR (DMSO- $\left.d_{6}, \delta\right): 2.00(\mathrm{~s}, 3 \mathrm{H}), 5.50-5.85$ (m, 1H), 6.98-7.68 (m, 14H), 7.91 (br, 1H), 9.91 (br, 1H). IR (KBr): $3380(\mathrm{~N}-\mathrm{H}), 1778,1721$
( $\mathrm{C}=\mathrm{O}$, imide ring), $1670(\mathrm{C}=\mathrm{O}$, amide), 1373 $\mathrm{cm}^{-1}(\mathrm{C}-\mathrm{N}$, imide).

\section{Preparation of Polymer PEI-3}

A solution of PEI-1 (100 mg, $240 \mu \mathrm{mol})$, benzoic acid (120 mg, $980 \mu \mathrm{mol}), \mathrm{LiCl}(20 \mathrm{mg})$, and TPP $(60 \mu \mathrm{L}, 240 \mu \mathrm{mol})$ in NMP/pyridine $(2.5 \mathrm{~mL}, 4: 1$ $\mathrm{v} / \mathrm{v})$ was heated at $110^{\circ} \mathrm{C}$ under nitrogen for $12 \mathrm{~h}$. The resulting solution was added dropwise to methanol $(50 \mathrm{~mL})$ with agitation. The polymer was collected by filtration, purified twice by reprecipitation from DMF into methanol, and dried in vacuo to give PEI-3 (120 mg, 92\%).

${ }^{1} \mathrm{H}$ NMR (DMSO- $\left.d_{6}, \delta\right): 5.59-5.84(\mathrm{~m}, 1 \mathrm{H})$, 6.95-8.10 (m, 20H), 10.26 (br, 1H). IR (KBr): 3380 $(\mathrm{N}-\mathrm{H}), \quad 1778,1721(\mathrm{C}=\mathrm{O}$, imide ring $), 1665$ $(\mathrm{C}=\mathrm{O}$, amide $), 1373 \mathrm{~cm}^{-1}(\mathrm{C}-\mathrm{N}$, imide $)$.

\section{Preparation of Polymer PEI-4}

PEI-4 was prepared from PEI-1 (100 mg, 240 $\mu \mathrm{mol}$ ) and 4-n-octylbenzoic acid (170 mg, 726 $\mu \mathrm{mol})$ with the same procedure used for the preparation of PEI-3.

Yield: $144 \mathrm{mg}, 95 \% .{ }^{1} \mathrm{H}$ NMR (DMSO- $d_{6}, \delta$ ): 0.55-1.63 (m, 15H), 2.61 (br, 2H), 5.58-5.84 (m, 1H), 7.02-7.42 (m, 12H), 7.63-8.00 (m, 7H), 10.14 (br, 1H). IR (KBr): $3375(\mathrm{~N}-\mathrm{H}), 1778,1721$ ( $\mathrm{C}=\mathrm{O}$, imide ring), $1665(\mathrm{C}=\mathrm{O}$, amide), 1373 $\mathrm{cm}^{-1}(\mathrm{C}-\mathrm{N}$, imide).

\section{Preparation of Polymer PEI-5}

A solution of PEI-1 (100 mg, $240 \mu \mathrm{mol})$ and phthalic anhydride (150 mg, $1.01 \mathrm{mmol}$ ) in DMAc $(2.0 \mathrm{~mL})$ was heated at $110^{\circ} \mathrm{C}$ under nitrogen for $12 \mathrm{~h}$. The resulting solution was added dropwise to a methanol solution (50 $\mathrm{mL})$ with agitation. The polymer was collected by filtration, purified twice by reprecipitation from DMF into methanol, and dried in vacuo to give PEI-5 (117 mg, 89\%).

${ }^{1} \mathrm{H}$ NMR (DMSO- $\left.d_{6}, \delta\right): 5.84(\mathrm{br}, 1 \mathrm{H}), 7.02-7.45$ (m, 14H), 7.78-8.00 (m, 5H). IR (KBr): 1778, 1721 $\left(\mathrm{C}=\mathrm{O}\right.$, imide ring), $1373 \mathrm{~cm}^{-1}(\mathrm{C}-\mathrm{N}$, imide $)$.

\section{Preparation of Poly(ether imide)/Polyhedral Oligomeric Silsesquioxane (PEI-POSS)}

A solution of POSS-BzCl (160 mg, $154 \mu \mathrm{mol})$ in tetrahydrofuran ( $\mathrm{THF} ; 2.0 \mathrm{~mL}$ ) was added to a mixture of PEI-1 (60 mg, $0.14 \mathrm{mmol}$ ), $\mathrm{K}_{2} \mathrm{CO}_{3}$ (133 $\mathrm{mg}, 0.96 \mathrm{mmol}$ ), and $\mathrm{NaI}$ (40 $\mathrm{mg}, 0.27 \mathrm{mmol}$ ) in DMF $(2.0 \mathrm{~mL})$. The reaction mixture was heated 


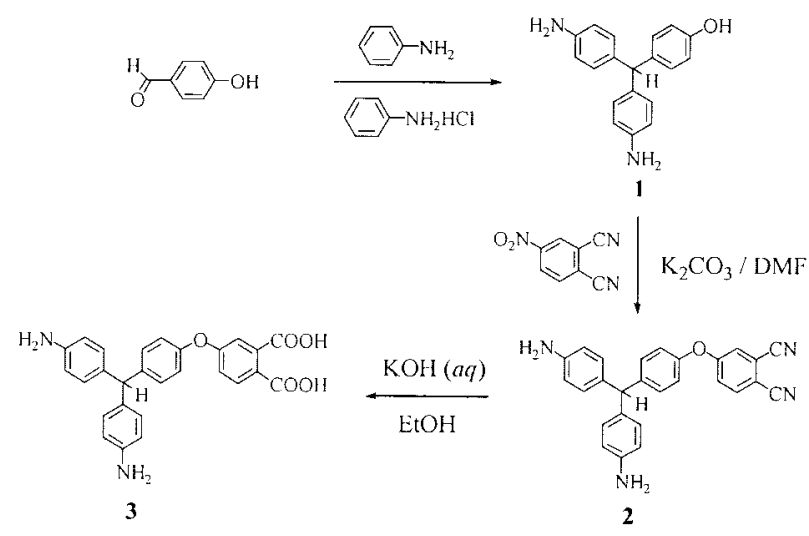

Scheme 1

at $70{ }^{\circ} \mathrm{C}$ for $12 \mathrm{~h}$. The resulting solution was added dropwise to $n$-hexane $(50 \mathrm{~mL})$ with agitation to remove the ungrafted POSS-BzCl. The precipitate was collected by filtration, washed with $n$-hexane, purified twice by reprecipitation from THF into methanol, and dried in vacuo to give PEI-POSS (120 mg, 56\%).

${ }^{1} \mathrm{H}$ NMR (THF- $\left.d_{8}, \delta\right): 0.70-2.15(\mathrm{~m}, 77 \mathrm{H}), 4.33$ (br, 2H), 5.20-5.60 (m, 1H), 6.45-8.00 (m, 19H). IR $(\mathrm{KBr}): 3390(\mathrm{~N}-\mathrm{H}), 1778,1716(\mathrm{C}=\mathrm{O}$, imide ring), $1373 \mathrm{~cm}^{-1}(\mathrm{C}-\mathrm{N}$, imide).

\section{RESULTS AND DISCUSSION}

\section{Monomer Synthesis}

The synthesis of the $\mathrm{AB}_{2}$-type monomer 3 is outlined in Scheme 1. The acid-catalyzed condensation of 4-hydroxybenzaldehyde with an excess of aniline gave $1 .^{32}$ The nucleophilic substitution of the nitro function of 4-nitrophthalonitrile by the phenoxide group generated from $\mathbf{1}$ in the presence of $\mathrm{K}_{2} \mathrm{CO}_{3}$ in DMF furnished the phthalonitrile compound 2, which subsequently, on hydrolysis with aqueous $\mathrm{KOH}$ in ethanol, afforded the desired 3. The $\mathrm{AB}_{2}$-type monomer contained one phthalic acid group and two aminophenyl functionalities. The structures of the synthesized compounds were verified with ${ }^{1} \mathrm{H}$ and ${ }^{13} \mathrm{C}$ NMR spectroscopy and mass spectroscopy.

\section{Polymer Synthesis}

The one-step polymerization of monomer 3 was performed (Scheme 2) in NMP/pyridine at $150{ }^{\circ} \mathrm{C}$ for $12 \mathrm{~h}$, in the presence of equimolar amounts of TPP as an activator, to obtain quantitatively the hyperbranched poly(ether imide) PEI-1 containing terminal aminophenyl groups. The molecular weight of PEI-1 was determined by GPC with $\mathrm{DMF} / \mathrm{LiBr}(0.05 \mathrm{M})$ as the eluent, calibrated against poly(methyl methacrylate) standards. GPC analysis shows that the weight-average molecular weight $\left(M_{\mathrm{w}}\right)$ and polydispersity [weightaverage molecular weight/number-average molecular weight $\left.\left(M_{\mathrm{w}} / M_{\mathrm{n}}\right)\right]$ of the polymer were approximately $7.5 \times 10^{4} \mathrm{~g} / \mathrm{mol}$ and 4.6 , respectively. These values, however, were only indicative of the polymer size and weight distribution because the highly branched nature of PEI-1 may have caused it to deviate strongly when measured against linear, coil-like poly(methyl methacrylate) standards. The degree of polymerization was dependent on the reaction time. The wide molecular weight distribution of the hyperbranched poly(ether imide) broadened with increasing conversion. For example, as the reaction time proceeded from 3 to $9 \mathrm{~h}$, both $M_{\mathrm{w}}$ and $M_{\mathrm{w}} / M_{\mathrm{n}}$ of the obtained polymers increased from 1.8 to $3.8 \times 10^{4} \mathrm{~g} / \mathrm{mol}$ and from 2.6 to 3.9 , respectively. The broadening of the molecular weight distribution resembled that of the previous reports of other hyperbranched polymers and agreed with Flory's predictions concerning molecular weight distribution behavior for highly branched systems. $., 33,34$

The structure of PEI-1 was characterized by FTIR spectroscopy. The absence of the $\mathrm{C}=\mathrm{O}$ vibrational band at $1670 \mathrm{~cm}^{-1}$ of poly(amic acid) indicated that imide formation was complete. The polymer exhibited characteristic carbonyl absorptions corresponding to an imide ring at 1778 $(\mathrm{C}=\mathrm{O}$ asymmetric stretching $)$ and $1721 \mathrm{~cm}^{-1}$ $(\mathrm{C}=\mathrm{O}$ symmetric stretching), as well as the typical aromatic-imide $\mathrm{C}-\mathrm{N}$ stretching mode at 1373 $\mathrm{cm}^{-1}$. Furthermore, the peaks at 3457 and 3365 $\mathrm{cm}^{-1}$ were attributed to the terminal amino groups. The thermal properties of the hyperbranched poly(ether imide) were investigated by DSC and thermogravimetry measurements. From the DSC measurement, $T_{\mathrm{g}}$ of PEI-1 was detected at $280{ }^{\circ} \mathrm{C}$. TGA revealed that PEI-1 had high thermal stability, with a 5 wt \% loss ob-

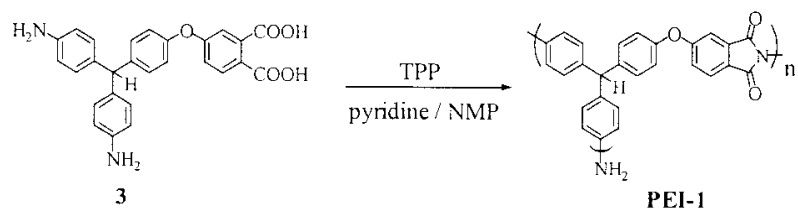

Scheme 2 


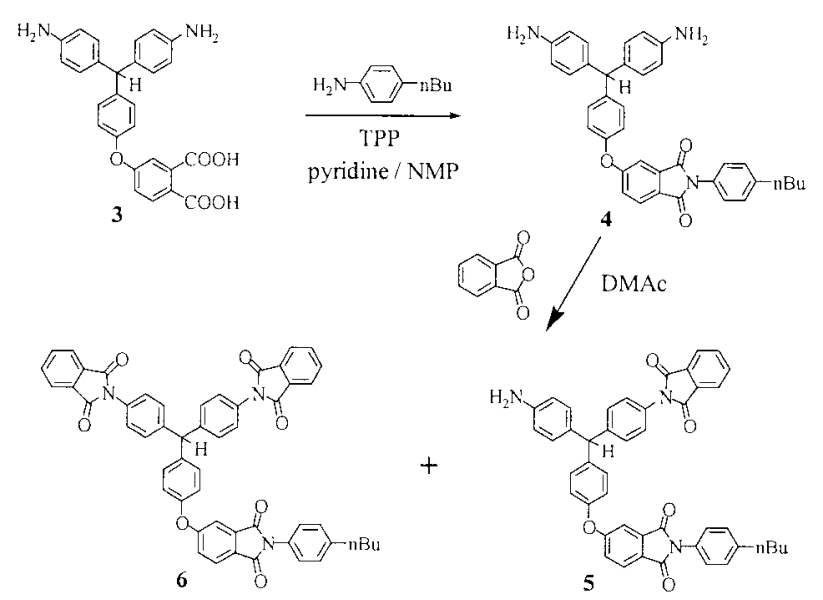

Scheme 3

served at $487{ }^{\circ} \mathrm{C}$ followed by a $10 \mathrm{wt} \%$ loss at $544^{\circ} \mathrm{C}$.

\section{DB}

Hyperbranched polymer PEI-1 was formed by a sequential condensation of the $\mathrm{AB}_{2}$ monomer and resulted in an irregular dendritic structure in which three different types of subunits (i.e., terminal, linear, and dendritic) could be present. DB, a typical characteristic often used to evaluate the structural irregularity of hyperbranched polymers, is defined as the sum of dendritic and terminal units relative to the total number of units. ${ }^{35,36}$ A combination of studies of model compounds and NMR spectroscopy was used to quantify the different subunits present in the hyperbranched polymer and, subsequently, to determine its $\mathrm{DB}^{35}$ The preparation of model compounds used for NMR spectroscopy characterization is illustrated in Scheme 3. Model compounds $\mathbf{4}, \mathbf{5}$, and $\mathbf{6}$ resemble the terminal unit, the linear unit, and the dendritic unit, respectively, and their ${ }^{1} \mathrm{H}$ NMR spectra are shown in Figure 1.

The chemical shift of the methine proton is sensitive to the number of aminophenyl groups attached to the methine carbon atom. A distinct resonance of the methine proton for the terminal model compound 4 appears at $5.23 \mathrm{ppm}\left(\mathrm{H}_{\mathrm{t}}\right)$, whereas resonances of the corresponding protons of the linear (5) and dendritic (6) model compounds can be observed at $5.54\left(\mathrm{H}_{1}\right)$ and $5.87\left(\mathrm{H}_{\mathrm{d}}\right)$ ppm, respectively. In addition, two pairs of $A B$ quartets, observed at $\delta=6.49 / 6.76 \mathrm{ppm}$ and $\delta$ $=6.53 / 6.84 \mathrm{ppm}$, can be attributed to the protons of the aminophenylene rings $\left(\mathrm{H}_{b}\right.$ and $\left.\mathrm{H}_{c}\right)$ for model compounds $\mathbf{4}$ and $\mathbf{5}$, respectively. Figure 1 also shows the ${ }^{1} \mathrm{H}$ NMR spectrum of the hyperbranched poly(ether imide). A good correlation is found between the ${ }^{1} \mathrm{H}$ NMR spectrum of PEI-1 and those of the model compounds. The resonances at 5.22, 5.52, and $5.82 \mathrm{ppm}$ can be attributed to the methine protons of the terminal, linear, and dendritic subunits, respectively, in the hyperbranched polymer. The resonances at 6.42 6.58 and 6.70-6.88 ppm are due to $\mathrm{H}_{\mathrm{b}}$ and $\mathrm{H}_{\mathrm{c}}$ of the terminal and linear subunits. The integration of these well-resolved resonances allowed the relative percentage of each subunit in PEI-1 to be determined. DB of the hyperbranched poly(ether imide) PEI-1 was estimated to be $56 \%$ on the basis of the relative integrations of these signals. ${ }^{35}$ It should be noted that the percentage estimated for the terminal subunit was approximately equal to that for the dendritic subunit. This result is consistent with the theoretical prediction that the number of dendritic units is equal to the number of terminal units for an $\mathrm{AB}_{2}$-type hyperbranched polymer possessing a high molecular weight. ${ }^{5}$

\section{Chemical Modification}

Hyperbranched polymers are characterized by a large number of chain-terminating groups. The

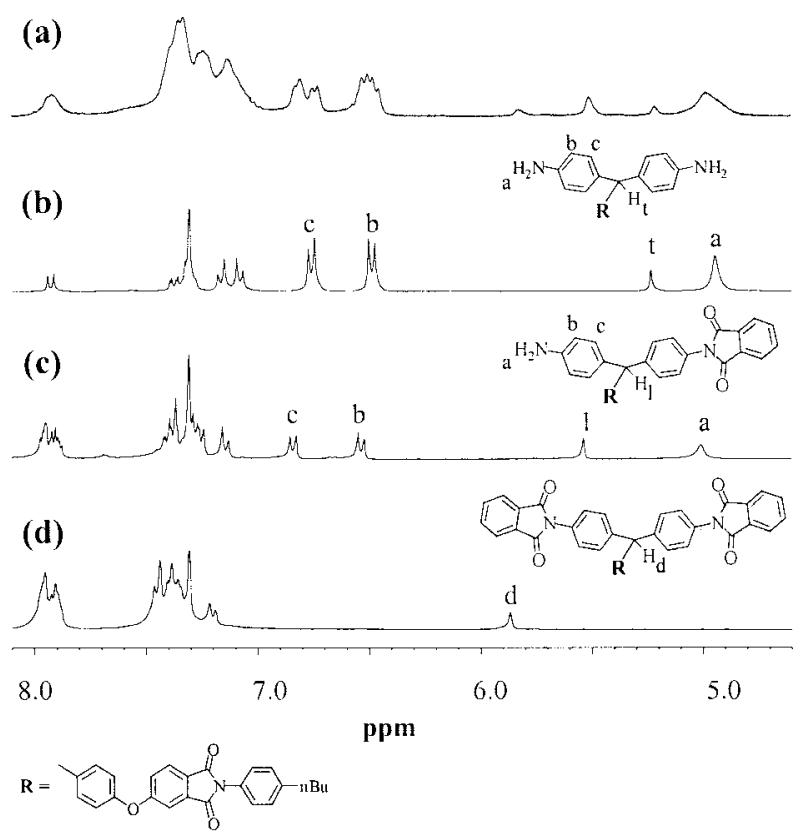

Figure 1. ${ }^{1} \mathrm{H}$ NMR spectra in DMSO- $d_{6}$ of (a) PEI-1 and model compounds (b) 4, (c) 5, and (d) 6 . 


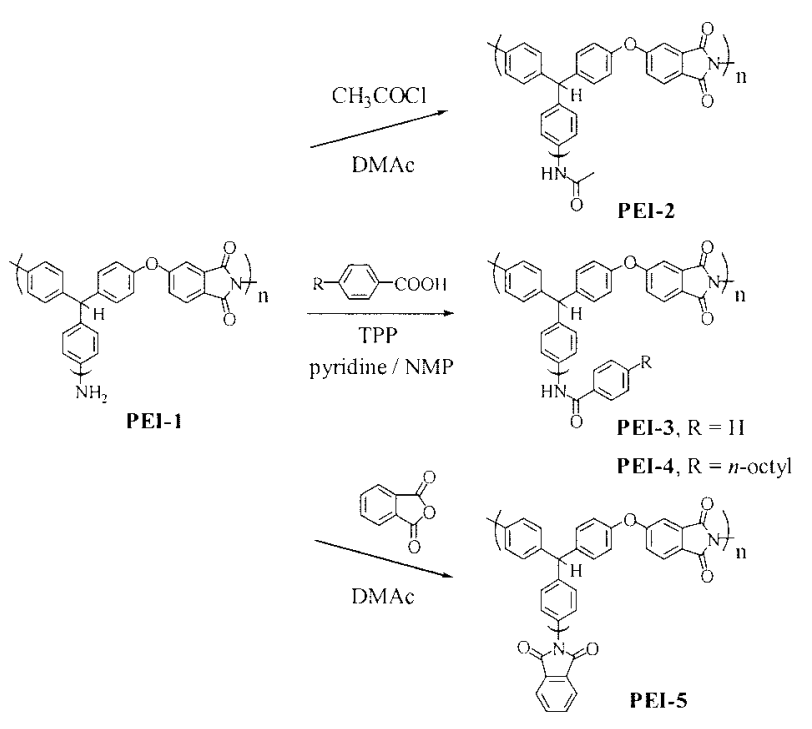

Scheme 4

terminal amino groups in PEI-1 were easily functionalized to yield hyperbranched polymers with a variety of functional end groups. As shown in Scheme 4, the amino end groups of PEI-1 were reacted with either an acid chloride or an acid in the presence of TPP as an activator to give the corresponding amide/imide derivatives PEI-2 to PEI-4. Upon reaction with phthalic anhydride, the amino groups were converted into phthalimide units to yield the imide derivative PEI-5. The successful modification of the end groups of PEI-1 was confirmed by the ${ }^{1} \mathrm{H}$ NMR spectra of the derivatives. Resonances associated with the protons of the aminophenyl groups disappeared entirely after end capping. The resonances of the protons of the amide groups of PEI-2 to PEI-4 appear in the region of 9.9-10.2 ppm. We note that the signals corresponding to the methine protons of the terminal, linear, and dendritic subunits of PEI-5 appear together as a broad peak at
$5.84 \mathrm{ppm}$. We attribute this feature to the similar chemical environments experienced by the three different subunits, which resemble the dendritic subunit, after the modification reaction is complete. The analysis of the integrations of the ${ }^{1} \mathrm{H}$ NMR spectra of the derivatives indicates that the modification reactions proceeded almost quantitatively ( $>95 \%)$.

The nature of the end groups influences the physical and chemical properties of hyperbranched polymers. ${ }^{37}$ Table 1 summarizes the solubility and thermal properties of the hyperbranched poly(ether imide)s PEI-1 to PEI-5. Because of their highly branched structures, these poly(ether imide)s had enhanced solubility in organic solvents and were highly soluble in polar solvents such as DMAc, DMF, NMP, and pyridine. The incorporation of different chain ends, however, led to differences in solubility in very polar and relatively nonpolar solvents. PEI-1 to PEI-3 and PEI-5 were soluble in DMSO, whereas PEI-4, which possessed flexible $n$-octyl chain-ending groups, was soluble in DMSO only upon heating. Conversely, in solvents such as chloroform and dichloromethane, polymers PEI-1 to PEI-3 were completely insoluble, PEI-4 was soluble in chloroform and soluble in dichloromethane upon heating, and PEI-5 was soluble in both solvents. In THF, only PEI-4 was soluble. It is known that the transition from polar end groups to nonpolar end groups results in a decrease in the value of $T_{\mathrm{g}}$ for hyperbranched polymers because of a reduction in the extent of intermolecular interactions between polymer molecules. ${ }^{38}$ As revealed by DSC measurements, $T_{\mathrm{g}}$ of PEI-1, which had polar amino terminal groups, was $280^{\circ} \mathrm{C}$, whereas the $T_{\mathrm{g}}$ values of PEI-3 and PEI-5, which had less polar terminal groups (amide and imide groups), were 240 and $267{ }^{\circ} \mathrm{C}$, respectively. The lowering of $T_{\mathrm{g}}$ was caused by a decrease in the extent of

Table 1. Thermal and Solubility Properties of Hyperbranched Poly(ether imide)s

\begin{tabular}{lcccccc}
\hline & & \multicolumn{5}{c}{ Solubility $^{\mathrm{a}}$} \\
\cline { 3 - 7 } Polymer & $T_{\mathrm{g}}\left({ }^{\circ} \mathrm{C}\right)$ & $\mathrm{CHCl}_{3}$ & $\mathrm{CH}_{2} \mathrm{Cl}_{2}$ & $\mathrm{THF}$ & $\mathrm{DMF}$ & DMSO \\
\hline PEI-1 & 280 & - & - & - & + & + \\
PEI-2 & 214 & - & - & - & + & + \\
PEI-3 & 240 & - & - & - & + & + \\
PEI-4 & 192 & + & \pm & + & + & \pm \\
PEI-5 & 267 & + & + & - & + & + \\
\hline
\end{tabular}

$\mathrm{a}+=$ soluble $;-=$ insoluble $\pm=$ soluble on heating. 


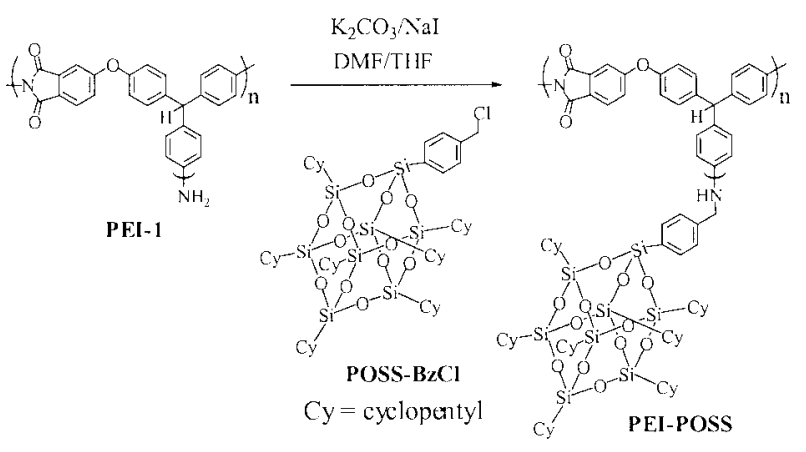

Scheme 5

hydrogen bonding. Further decreases in the values of $T_{\mathrm{g}}$, to 214 and $192{ }^{\circ} \mathrm{C}$, were observed for PEI-2 and PEI-4, respectively, brought about by the replacement of the phenyl group with a methyl group and the introduction of flexible $n$ octyl chain termini. Polymers PEI-1 to PEI-5 possessed good thermal stability, as evidenced by TGA. The $10 \%$ weight loss occurred in the range of $486-547{ }^{\circ} \mathrm{C}$ under a nitrogen atmosphere. PEI-4, which had long alkyl chain end groups, exhibited the lowest decomposition temperature.

\section{PEI-POSS}

Organic-inorganic nanocomposite materials have been the subject of considerable attention because of their potential to bridge the gap between organic polymers and inorganic ceramics. ${ }^{31,39,40}$ One class of inorganic materials (POSS) has a nanometer-sized structure with a high surface area and controlled porosity and is suitable for designing hybrid materials with various functions. POSS consists of a rigid, cubic silica core $\left(\mathrm{Si}_{8} \mathrm{O}_{12}\right)$ surrounded by eight organic groups, of which seven are inert and one is reactive. ${ }^{41}$ Through this one reactive site, POSS molecules have been successfully incorporated as nanosize inorganic pendants into linear organic polymers, such as poly(methyl methacrylate), ${ }^{42} \operatorname{poly}(4-$ methylstyrene), ${ }^{43}$ polynorbornene, ${ }^{44,45}$ and polyurethane. ${ }^{46}$

We introduced silsesquioxane cubes into the hyperbranched poly(ether imide) by the reaction of the amino end groups with $\mathrm{POSS}-\mathrm{BzCl}$ to give an organic-inorganic hybrid material (PEIPOSS; Scheme 5). We used 1.1 equiv of the POSS reagent for the grafting reaction. When the reaction was complete, the resulting polymer solution was precipitated into $n$-hexane to remove the unreacted POSS-BzCl. The degree of POSS incorpo- ration in the hybrid material was estimated to be about $80 \mathrm{~mol} \%$ by ${ }^{1} \mathrm{H}$ NMR spectroscopy, based on the ratio between the integrals of the cyclopentyl signals of the POSS unit and the sum of the aromatic signals. The morphology of the hybrid material PEI-POSS was examined by means of TEM. The high density of the Si atom of POSS allowed direct imaging without the need for conventional staining. Figure 2 shows the TEM micrograph of a sample prepared by the dripping of the polymer solution ( $5 \mathrm{wt} \%$ in THF) onto a 200-mesh copper net coated with a carbon film and drying in air. The hybrid material self-assembled to form defined core-shell-structured spheres with diameters ranging from 80 to 120 $\mathrm{nm}$. The inner core was about 60-100 nm wide, consisting of the hyperbranched poly(ether imide) and POSS molecules attached to the interior branches of poly(ether imide). The thickness of the outer shell of these spheres was about 10-15 $\mathrm{nm}$, which suggested that the aggregated POSS molecules were positioned at the peripheries of the exterior. Because the dipole-dipole interactions between imide segments were quite different from the interactions between POSS molecules, the grafting of POSS molecules to the termini of the hyperbranched poly(ether imide) chains led to a phase-separated system. Additionally, the interchain and/or intrachain POSSPOSS interactions resulted in variations in the

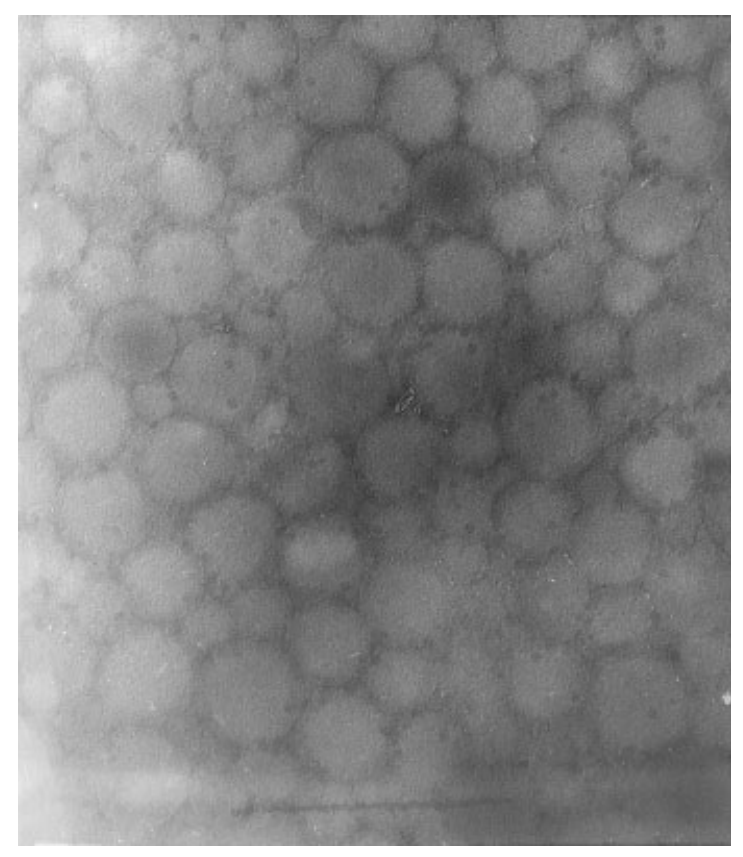

Figure 2. TEM micrograph of PEI-POSS. 
aggregate solubility. For example, PEI-POSS was completely soluble only in a mixture of THF and DMF and was partially soluble in THF. These results suggest that the grafted POSS molecules probably aggregated to form a nanoscale composite material; this supports a method for preparing materials with well-defined architectures.

\section{CONCLUSIONS}

The direct self-polycondensation of a new $\mathrm{AB}_{2^{-}}$ type monomer (3), which contained one phthalic acid group and two aminophenyl functionalities, in the presence of TPP as an activator gave a hyperbranched poly(ether imide) with chain-ending amino groups. We estimated DB to be $56 \%$ on the basis of ${ }^{1} \mathrm{H}$ NMR spectral analysis. The poly(ether imide) exhibited good solubility in common organic solvents, such as NMP, DMF, pyridine, and DMSO, which we attributed to its highly branched structure. The amino groups at the ends of the chains were readily accessible to reagents in solution and were converted into a variety of functional groups. The nature of the end groups significantly affected the solubility and thermal properties of the hyperbranched poly(ether imide)s. Additionally, the chain-ending amino groups of the hyperbranched poly(ether imide) were grafted with POSS molecules. TEM analysis revealed that the resulting hybrid material selfassembled to form core-shell structures with total diameters ranging from 80 to $120 \mathrm{~nm}$ and shell thicknesses of $10-15 \mathrm{~nm}$. This result indicated that the grafted POSS molecules aggregated to form a nanocomposite material with a well-defined architecture.

The authors thank the National Science Council of the Republic of China for its financial support.

\section{REFERENCES AND NOTES}

1. Malmström, E.; Hult, A. J Macromol Sci Rev Macromol Chem Phys 1997, 37, 555.

2. Kim, Y. H. J Polym Sci Part A: Polym Chem 1998, $36,1685$.

3. Voit, B. J Polym Sci Part A: Polym Chem 2000, 38, 2505.

4. Jikei, M.; Kakimoto, M. Prog Polym Sci 2001, 26, 1233 and references therein.

5. Flory, P. J. J Am Chem Soc 1952, 74, 2718.
6. Tomalia, D. A.; Naylor, A. M.; Goddard, W. A., III. Angew Chem Int Ed Engl 1990, 29, 138.

7. Fréchet, J. M. J. Science 1994, 263, 1710.

8. Newkome, G. R.; Moorefield, C. N.; Vögtle, F. Dendritic Molecules: Concepts, Syntheses, Perspectives; VCH: Weinheim, 1996.

9. Hecht, S.; Fréchet, J. M. J. Angew Chem Int Ed Engl 2001, 40, 74.

10. Tomalia, D. A.; Fréchet, J. M. J. J Polym Sci Part A: Polym Chem 2002, 40, 2719.

11. Tomalia, D. A.; Baker, H.; Dewald, J.; Hall, M.; Kallos, G.; Martin, S.; Roeck, J.; Ryder, J.; Smith, P. Polym J 1985, 17, 117.

12. Newkome, G. R.; Yao, Z.-Q.; Baker, G. R.; Gupta, V. K. J Org Chem 1985, 50, 2003.

13. Hawker, C. J.; Fréchet, J. M. J. J Am Chem Soc 1990, 112, 7638.

14. Xu, Z. F.; Moore, J. S. Angew Chem Int Ed Engl 1993, 32, 1354.

15. Polyimides; Wilson, D.; Stenzenberzer, H. D.; Hergenrother, P. M., Eds.; Blackie: New York, 1990.

16. Polyimides: Fundamentals and Applications; Ghosh, M. K.; Mittal, K. L., Eds.; Marcel Dekker: New York, 1996.

17. Harris, F. W. In Polyimides; Wilson, D.; Stenzenberger, H. D.; Hergenrother, P. M., Eds.; Blackie: New York, 1990; Chapter 1.

18. White, D. M.; Takekoshi, T.; Williams, F. J.; Relles, H. M.; Donahue, P. E.; Klopfer, H. J.; Louks, G. R.; Manello, J. S.; Matthews, R. O.; Schluenz, R. W. J Polym Sci Polym Chem Ed 1981, 19, 1635.

19. Thompson, D. S.; Markoski, L. J.; Moore, J. S. Macromolecules 1999, 32, 4764.

20. Markoski, L. J.; Thompson, J. L.; Moore, J. S. Macromolecules 2000, 33, 5315.

21. Orlicki, J. A.; Thompson, J. L.; Markoski, L. J.; Sill, K. N.; Moore, J. S. J Polym Sci Part A: Polym Chem 2002, 40, 936.

22. Yamanaka, K.; Jikei, M.; Kakimoto, M. Macromolecules 2000, 33, 1111.

23. Yamanaka, K.; Jikei, M.; Kakimoto, M. Macromolecules 2000, 33, 6937.

24. Yamanaka, K.; Jikei, M.; Kakimoto, M. Macromolecules 2001, 34, 3910.

25. Wu, F.-I.; Shu, C.-F. J Polym Sci Part A: Polym Chem 2001, 39, 2536.

26. Fang, J.; Kita, H.; Okamoto, K. Macromolecules 2000, 33, 4639.

27. Hao, J.; Jikei, M.; Kakimoto, M. Macromolecules 2002, 35, 5372.

28. Chen, H.; Yin, J. J Polym Sci Part A: Polym Chem 2002, 40, 3804.

29. Liu, Y.; Chung, T.-S. J Polym Sci Part A: Polym Chem 2002, 40, 4563.

30. Im, J. K.; Jung, J. C. J Polym Sci Part A: Polym Chem 1999, 37, 3530. 
31. Sanchez, C.; Soler-Illia, G. J. de A. A.; Ribot, F.; Lalot, T.; Mayer, C. R.; Cabuil, V. Chem Mater 2001, 13, 3061.

32. Ueda, M.; Nakayama, T. Macromolecules 1996, 29, 6427.

33. Gong, Z.-H.; Leu, C.-M.; Wu, F.-I.; Shu, C.-F. Macromolecules 2000, 33, 8527.

34. Wu, F.-I.; Shu, C.-F. J Polym Sci Part A: Polym Chem 2001, 39, 3851.

35. Hawker, C. J.; Lee, R.; Fréchet, J. M. J. J Am Chem Soc 1991, 113, 4583.

36. Hölter, D.; Burgath, A.; Frey, H. Acta Polym 1997, 48, 30.

37. Hawker, C. J.; Chu, F. Macromolecules 1996, 29, 4370 .

38. Schmaljohann, D.; Häußler, L.; Pötschke, P.; Voit, B. I.; Loontjens, T. J. A. Macromol Chem Phys 2000, 201, 49.
39. Tsukruk, V. V. Prog Polym Sci 1997, 22, 247.

40. Klok, H. A.; Lecommandoux, S. Adv Mater 2001, 13, 1217.

41. Feher, F. J.; Weller, K. J.; Schwab, J. J. Organometallics 1995, 14, 2009.

42. Lichtenhan, J. D.; Otonari, Y. A.; Carr, M. J. Macromolecules 1995, 28, 8435.

43. Haddad, T. S.; Lichtenhan, J. D. Macromolecules 1996, 29, 7302 .

44. Mather, P. T.; Jeon, H. G.; Romo-Uribe, A.; Haddad, T. S.; Lichtenhan, J. D. Macromolecules 1999, 32, 1194.

45. Zheng, L.; Waddon, A. J.; Farris, R. J.; Coughlin, E. B. Macromolecules 2002, 35, 2375.

46. Fu, B. X.; Hsiao, B. S.; Pagola, S.; Stephens, P.; White, H.; Rafailovich, M.; Sokolov, J.; Mather, P. T.; Jeon, H. G.; Phillips, S.; Lichtenhan, J.; Schwab, J. Polymer 2001, 42, 599. 